\title{
Japan's Phillips Curve Looks Like Japan
}

Gregor W. Smith

Department of Economics, Queen's University, Canada

smithgw@econ.queensu.ca

May 2006

Keywords: Phillips curve, Japan

JEL codes: E31, E24

Figure 1 shows the Japanese Phillips curve. The data are monthly from January 1980 to August 2005. The inflation rate (on the vertical axis) is the 12-month growth rate in the consumer price index (all items), from the International Monetary Fund's International Financial Statistics. The monthly unemployment rate (on the horizontal axis) is from Econstats.

Someone once said that a country's institutions and history are reflected in its Phillips curve. For ease of viewing, figure 2 rotates the Phillips curve around the vertical axis so that minus the unemployment rate now is on the horizontal axis. Clearly visible are the islands of Hokkaido and Honshu, though it is somewhat difficult to separately distinguish the southern islands of Kyushu and Shikoku. The Noto-Hanto Penninsula is evident to the north of the southern end of the main island of Honshu. Tokyo Bay is also visible. The data point to the far left in figure 2 is the island of Fukue-Jima.

Figure 3 shows a map of Japan for purposes of confirmation.

Further research work on Phillips curves and the new macroeconomic geography will focus on Chile. McCall (2003) provides an alternative hypothesis at the continental level of aggregation.

\section{References}

McCall, Bruce (2003) All Meat Looks Like South America. New York: Crown. 
Figure 1: Japan's Inflation and Unemployment Rates January 1980 to August 2005

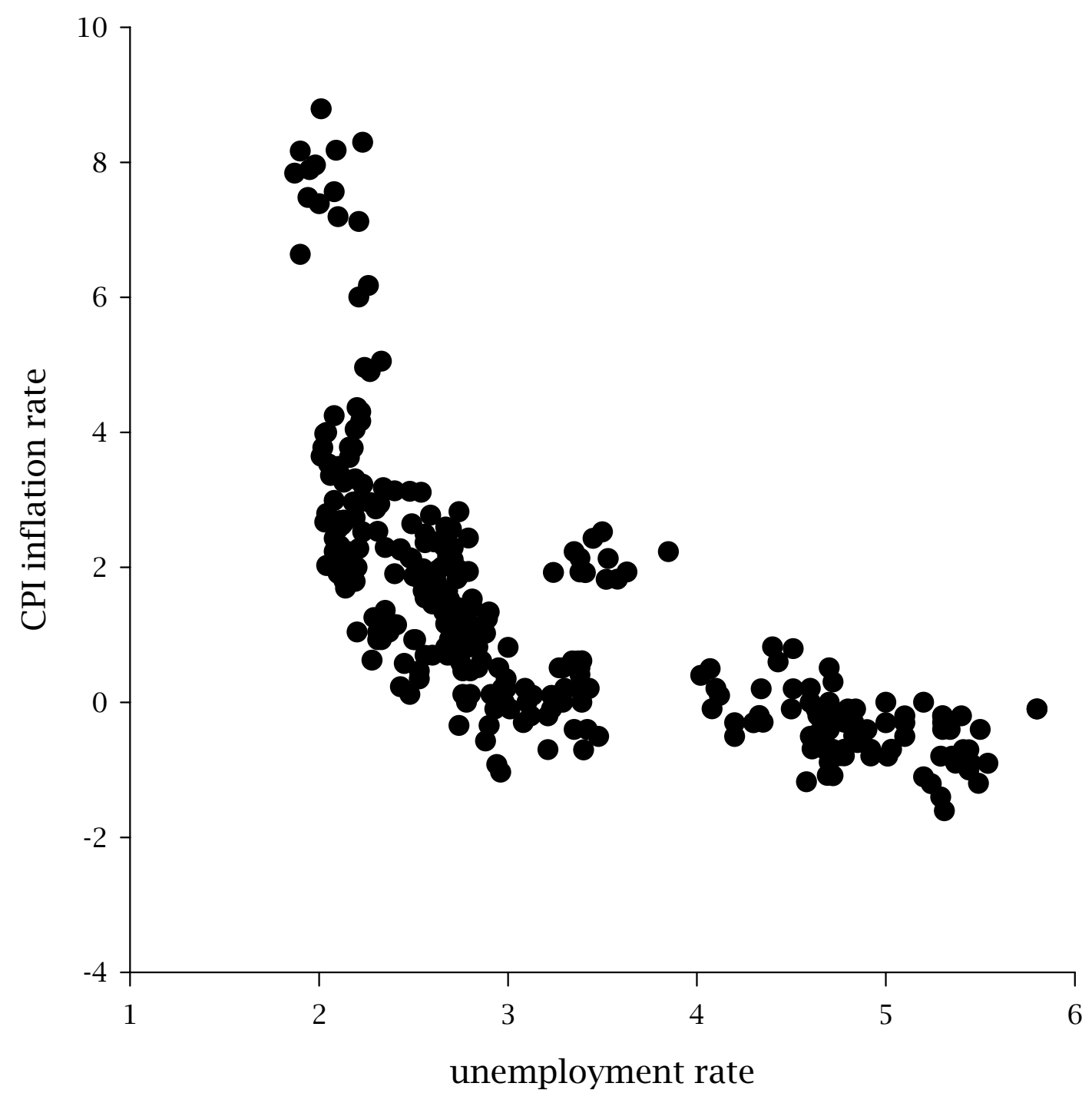


Figure 2: Japan's Inflation Rate and (Minus) Unemployment Rate January 1980 to August 2005

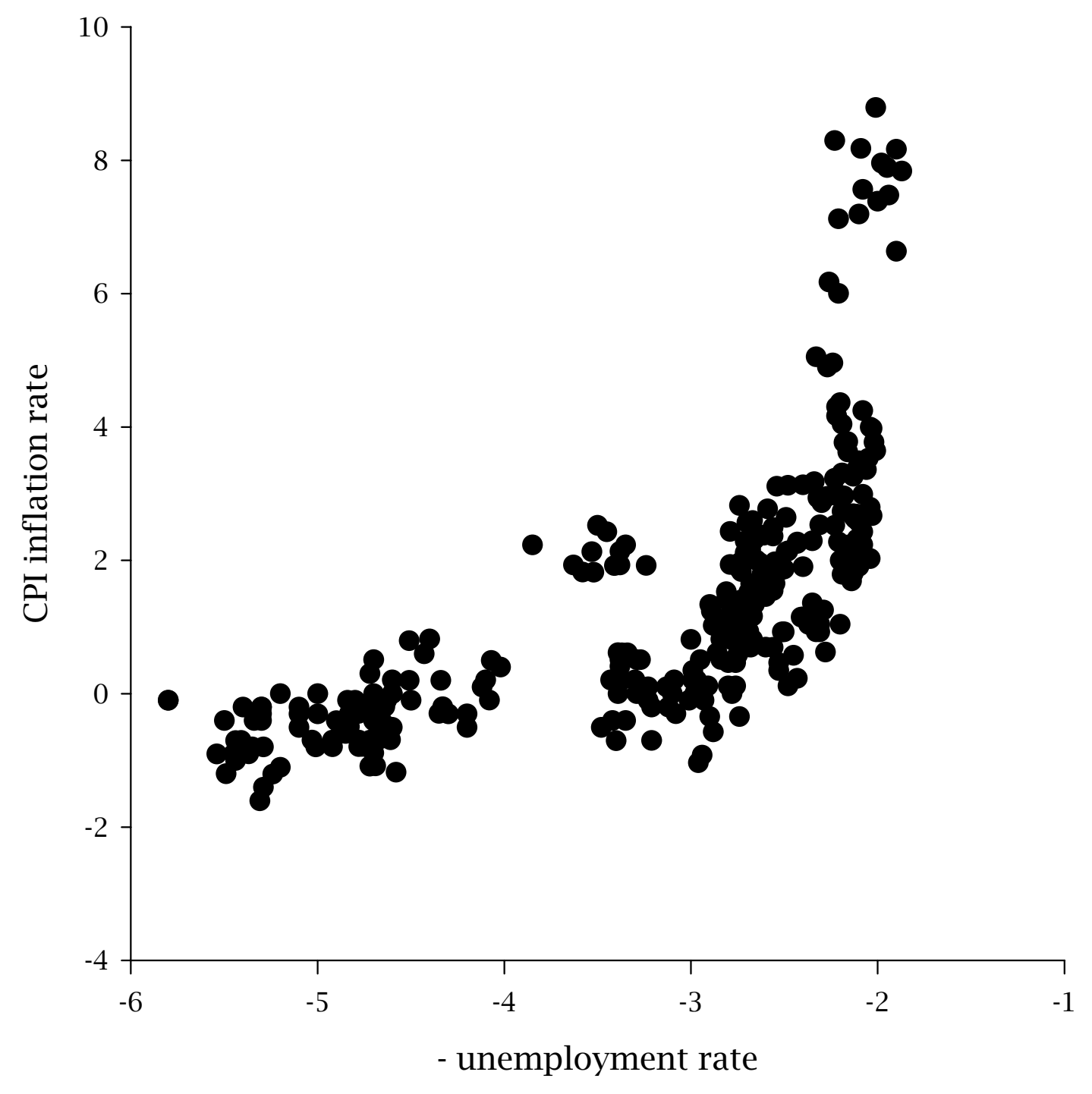




\section{Japan}

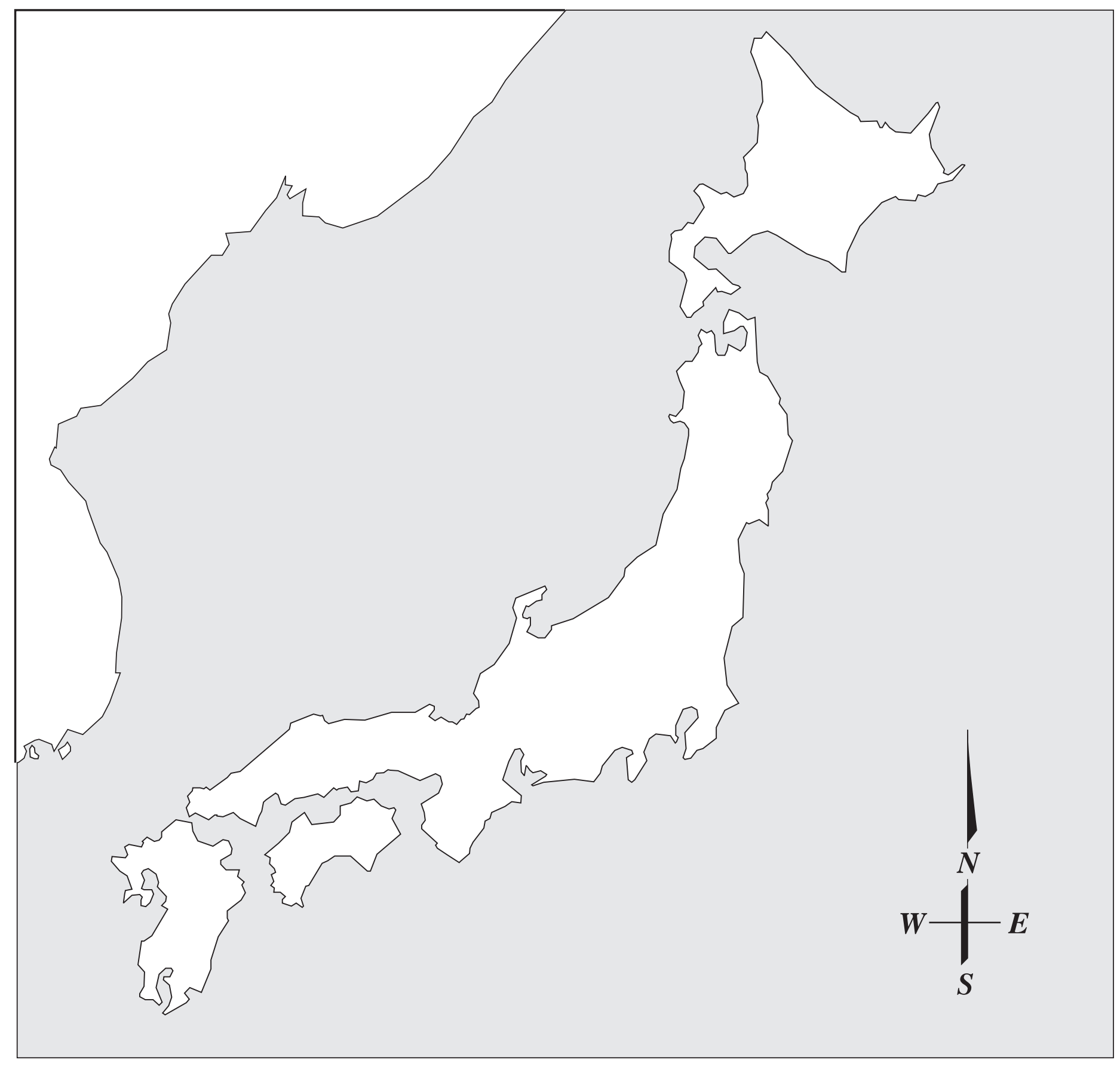

